\title{
Eye malformations in Cameroonian children: a clinical survey
}

\author{
This article was published in the following Dove Press journal: \\ Clinical Ophthalmology \\ 3 October 2012 \\ Number of times this article has been viewed
}

\author{
André Omgbwa Eballé1,2 \\ Augustin Ellong ${ }^{3}$ \\ Godefroy Koki ${ }^{3}$ \\ Ngoune Chantal Nanfack ${ }^{3}$ \\ Viola Andin Dohvoma ${ }^{3}$ \\ Côme Ebana Mrogo ${ }^{2,3}$ \\ 'Yaoundé Gynaecology, Obstetrics \\ and Pediatrics Hospital, Yaoundé, \\ Cameroon; ${ }^{2}$ Faculty of Medicine and \\ Pharmaceutical Sciences, University \\ of Douala, Cameroon; ${ }^{3}$ Faculty of \\ Medicine and Biomedical Sciences, \\ University of Yaoundé I, Cameroon
}

Correspondence: André Omgbwa Eballé Yaoundé Gynaecology, Obstetrics and Pediatrics Hospital, PO Box 4362,

Yaoundé, Cameroon

Tel +23799654 468

Email andyeballe@gmail.com
Summary: The aim of this work was to describe the clinical aspects of eye malformations observed at the ophthalmology unit of the Yaoundé Gynaecology, Obstetrics and Pediatrics Hospital.

Patients and methods: We carried out a retrospective study of all malformations of the eye and its adnexae observed among children aged 0-5 years who were seen at the ophthalmology unit from January 2003 to December 2009.

Results: Out of the 2254 children who were examined, $150(6.65 \%)$ presented eye malformations. The mean age was $14.40 \pm 4$ months. Eye malformations were diagnosed in $71.66 \%$ of cases during the first year of life. The most frequent malformations were congenital lacrimal duct obstruction $(66.66 \%)$, congenital cataract (10.9\%), congenital glaucoma (10.9\%), microphthalmos (5.03\%), and congenital ptosis (3.77\%).

Conclusion: Eye malformations among children can lead to visual impairment and are a cause for discomfort to children and parents. Therefore, systematic postnatal screening is recommended to enable early management.

Keywords: malformations, ophthalmology, child, Cameroon

\section{Introduction}

Oculo-orbital malformations are developmental anomalies of the eye and/or ocular adnexa. In Europe, its prevalence in the general population varies between 2.2 and 14 per 10,000 births. ${ }^{1}$ African studies have mainly reported cataract and congenital glaucoma as the most frequent types of eye malformations. ${ }^{2-4}$ Malformations of the eye and orbit can be isolated or associated with other systemic malformations. To the best of our knowledge, no previous study has been conducted on this subject in Cameroon.

The aim of this study was to describe the clinical aspects of a series of oculoorbital malformations among children seen at the ophthalmology unit of the Yaoundé Gynaecology, Obstetrics and Pediatrics Hospital.

\section{Patients and methods}

We carried out a retrospective study in which all children aged 0-5 years who were seen at the ophthalmology unit of the Yaoundé Gynaecology, Obstetrics and Pediatrics Hospital from January 2003 to December 2009 were included.

The medical records of all children diagnosed with a malformation of the eye and/or ocular adnexae were retained. In children with multiple malformations, individual malformations were recorded separately. 
The following variables were analyzed: age at first consultation (diagnosis), sex, and the various malformations observed. These variables were analysed using Microsoft (Redmond, WA) Office Excel 2007.

\section{Results}

A total of 2254 children aged $0-5$ years were examined in the ophthalmology unit during this period, and 150 of them were diagnosed with eye malformations, representing $6.65 \%$ of our consultations. There were 78 boys (52\%) and 72 girls (48\%), corresponding to a male-to-female ratio of 1.08 . The mean age was $14.40 \pm 4$ months. Eye malformations were diagnosed in $71.66 \%(n=107)$ of cases during the first year of life.

Table 1 presents the distribution of children according to the age at which their malformation was diagnosed. Diagnosis was made in $72.66 \%$ of cases $(n=109)$ during the first year of life, with $11.33 \%$ of cases $(n=12)$ diagnosed during the first month. Table 2 presents the various types of malformations. A total of 159 malformations were identified from the 150 files selected, considering that a child could present with one or several malformations. Congenital lacrimal duct obstruction (CLDO) was the most frequent malformation, with a total of 106 cases out of 159 (66.66\%). It was unilateral in 90 patients (84\%) and bilateral in 16 patients $(15.10 \%)$. Congenital cataract was second, with 17 cases $(10.69 \%)$, unilateral in $41.18 \%$ of cases $(n=7)$ and bilateral in $58.82 \%$ of cases $(n=10)$. Eight cases of congenital glaucoma were diagnosed $(5.03 \%)$; it was more frequent among boys (five boys against three girls). Both unilateral and bilateral congenital glaucoma occurred in equal proportions with four cases each. Congenital glaucoma was diagnosed in $62.5 \%(n=5)$ of cases before the age of 1 year and in $37.5 \%$ of cases $(n=3)$ between 1 and 3 years. With regards to microphthalmos, eight cases $(5.03 \%)$ were identified, of which three were unilateral and five bilateral. Six cases of ptosis $(3.77 \%)$ were recorded and one bilateral aniridia associated with a case of congenital glaucoma without an associated systemic anomaly.

Table I Distribution of children with respect to age at diagnosis

\begin{tabular}{lll}
\hline Age (months) & $\mathbf{n}$ & $\%$ \\
\hline $0-1$ & 17 & 11.33 \\
$>1-12$ & 92 & 61.33 \\
$>12-36$ & 31 & 20.7 \\
$>36-60$ & 10 & 6.7 \\
Total & 150 & 100 \\
\hline
\end{tabular}

Table 2 Congenital malformations observed

\begin{tabular}{lll}
\hline Malformations & $\mathbf{n}$ & $\%$ \\
\hline Congenital lacrimal duct obstruction & 106 & 66.66 \\
Congenital cataract & 17 & 10.9 \\
Congenital glaucoma & 8 & 5.03 \\
Microphthalmos & 8 & 5.03 \\
Congenital ptosis & 6 & 3.77 \\
Microcornea & 5 & 3.14 \\
Peter's anomaly & 2 & 1.25 \\
Bilateral aniridia & $\mathrm{I}$ & 0.63 \\
Bilateral anophthalmos & $\mathrm{I}$ & 0.63 \\
Bilateral congenital ectropion & $\mathrm{I}$ & 0.63 \\
Bilateral ectopia lentis & $\mathrm{I}$ & 0.63 \\
Telecanthus & $\mathrm{I}$ & 0.63 \\
Limbal dermoid (in Goldenhar syndrome) & $\mathrm{I}$ & 0.63 \\
Persistent primary hyperplastic vitreous & $\mathrm{I}$ & 0.63 \\
Total & $\mathrm{I} 59$ & 100 \\
\hline
\end{tabular}

\section{Discussion}

This study reveals 14 different types of eye malformations observed in 150 children. The relevance of this study lies in the fact that it is a pioneer study in this domain in Cameroon. It is intended to provide the basis for prospective studies that will specifically target each of the anomalies identified, especially the most frequent ones.

Different prevalences for eye malformations have been reported in different studies. A prevalence of $1.7 \%$ was reported in Nigeria by Lawan ${ }^{2}$ and $2.2 \%$ in the Democratic Republic of the Congo by Kaimbo Wa Kaimbo et al. ${ }^{5}$ The difference between these results may be explained by the heterogeneous nature of the study population in each study. The age group was $0-10$ years in the study carried out by Lawan; and $0-25$ years in that by Kaimbo Wa Kaimbo et al. Eye malformation represented $6.65 \%$ of all consultations in this study. The true prevalence of eye malformations could not be determined in this study because the total population served by this unit could not be easily assessed. The Yaoundé Gynaecology, Obstetrics and Pediatrics Hospital is a referral center for the management of mother-and-child diseases, and therefore the majority of children seen are referred cases. Both boys and girls are equally affected (ratio of 1.08). Several authors have reported that males are more affected. ${ }^{2-7}$

Late diagnosis, which was observed in this study, might be due to the lack of attention given to suspicion of eye malformations in infants by mothers and medical practitioners. These malformations may sometimes be taken for granted. On the contrary, studies carried out in Europe report a diagnosis rate of $80 \%$ during the first week of life. ${ }^{8,9}$ 
In this study, congenital CLDO was the most frequent malformation. This is contrary to the studies conducted by Lawan $^{2}$ and Bodunde and Ajibode, ${ }^{3}$ both in Nigeria, where CLDO was the third-commonest eye malformation after congenital cataract and congenital glaucoma. CLDO among children is most often caused by failure of Hasner's valve to open spontaneously..$^{10}$ The majority of cases resolve spontaneously during the first year of life with massage and local antibiotic therapy. ${ }^{11,12}$

Congenital cataract, which was the second most frequent malformation in this study, is the main cause of blindness and low vision among children. ${ }^{13}$ Mature forms require early surgery as well as long-term and rigorous management of amblyopia, which requires the participation of the child and his/her family. ${ }^{14}$ In immature forms allowing for visual development, surgery may be delayed until the child starts learning to read or even until it becomes impossible for normal schooling. ${ }^{14}$ Intrauterine infections by toxoplasmosis, rubella, cytomegalovirus, and herpes (TORCH) microorganisms, especially congenital rubella, are known for being responsible for congenital cataract. ${ }^{4,15}$ TORCH infection screening, although recommended during pregnancy, is not always done for several reasons: firstly, practitioners do not frequently request the tests, and secondly, even when requested, they are not done due to lack of means to pay. Cameroon is a developing country without a social security policy allowing for low-cost medical coverage.

Congenital glaucoma (Figure 1) was diagnosed in $62.5 \%$ of cases during the first year of life. This is less than those reported by several African studies, ${ }^{6,7,16}$ in which the

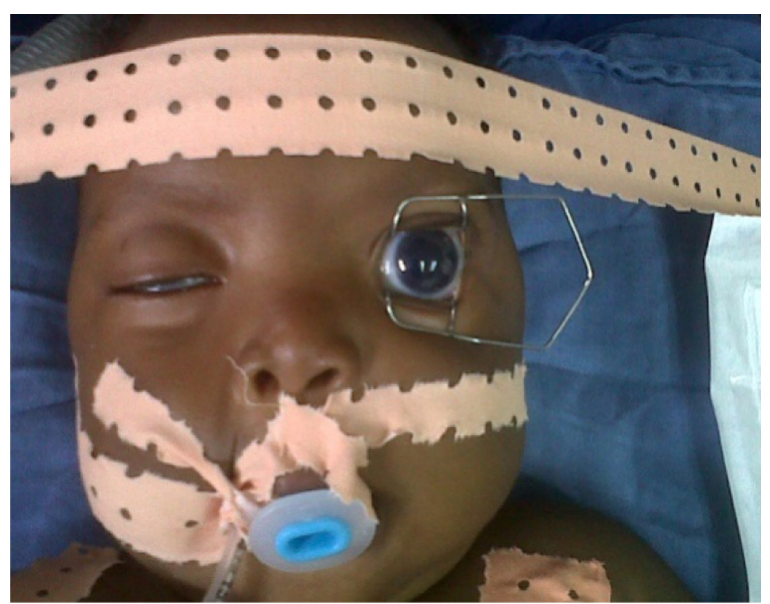

Figure I Buphthalmos and megalocornea in congenital glaucoma (photo, André Omgbwa Eballé, Cameroon). diagnosis was made in $73 \%-82 \%$ of cases during the first year of life. It is also lower than the result obtained by Zech and Ravault in Lyon, who reported $80 \%$ of cases before the age of 1 month. ${ }^{8}$ Congenital glaucoma presents a surgical emergency, but the delay in diagnosis and hence late management in the African context might be explained by the fact that parents are ignorant about the signs. The equal distribution between bilateral and unilateral forms is contrary to data published in the literature, where bilateral cases are more predominant. This predominance is explained by the hereditary nature of the illness. ${ }^{7-9}$

Microphthalmos was eight times more frequent than clinical anophthalmos (Figure 2), both of which are incompatible with normal visual development resulting from an arrest in the development of the primary optic vesicles at the embryonic stage. ${ }^{17}$

With regards to ptosis, its prevalence worldwide is unknown, and it is unilateral in most cases. ${ }^{18}$ In severe cases of ptosis, the drooping eyelid can cover part of or the entire pupil and interfere with vision, resulting in amblyopia. ${ }^{19}$

Bilateral aniridia is rare, with prevalence varing between $1 / 64,000$ and $1 / 100,000 .^{20,21}$ It is caused by a mutation in the PAX6 gene, located on human chromosome 11, and is usually associated with other eye and systemic anomalies. Cataract is found in $50 \%-85 \%$ of patients suffering from bilateral aniridia. ${ }^{20}$

Ectopia lentis, which is considered a major diagnostic criterion for Marfan's syndrome, ${ }^{22}$ was found in one patient. It is caused by a deficient development of the zonule, which like elastic tissue is of mesodermic origin. ${ }^{23}$

Goldenhar syndrome (Figure 3) also known as oculoauriculovertebral dysplasia, is a rare congenital anomaly involving derivatives of the first and second branchial arches. ${ }^{24}$ Its main ocular manifestation is limbal dermoid, which is



Figure 2 Congenital anophthalmos (photo, André Omgbwa Eballé, Cameroon). 
A

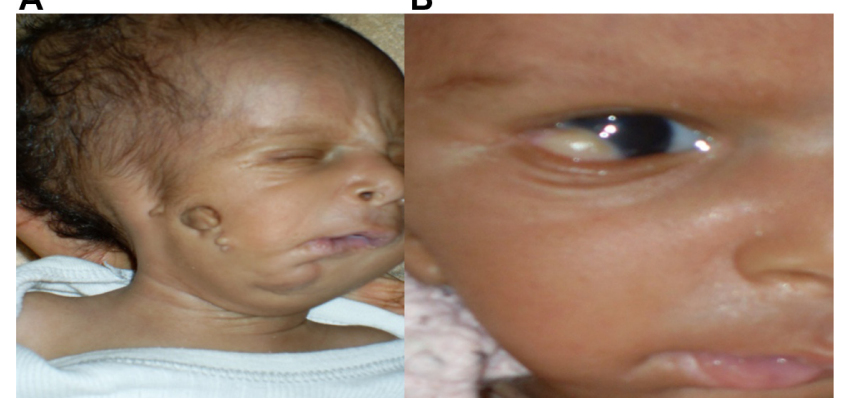

Figure 3 (A and B) Goldenhar syndrome (photo, André Omgbwa Eballé, Cameroon). (A) Mandibular hypoplasia and preauricular skin tag; (B) limbal dermoid in the same child.

found in $30 \%-60 \%$ of cases and is a cause of astigmatism, amblyopia, and strabismus. ${ }^{25}$

Persistent hyperplastic primary vitreous results from failure of the primary vitreous and hyaloid vasculature to regress. Its unilateral localization, which was found in this study, exists equally in literature, where it represents $90 \%$ of cases. ${ }^{26}$

Other malformations, such as cryptophthalmos, iris coloboma, and the Usher syndrome, described in the literature ${ }^{4,15}$ were not identified in this study.

\section{Conclusion}

Eye malformations in children may lead to visual impairment. Consequently, systematic postnatal screening for early detection and management are recommended. Close collaboration among pediatricians, general practitioners, and ophthalmologists for a multidisciplinary care approach is necessary.

\section{Disclosure}

The authors declare no conflicts of interest.

\section{References}

1. EUROCAT Working Group. EUROCAT Report 4: Surveillance of Congenital Anomalies 1980-1988. Brussels: Catholic University of Louvain; 1991:61-72.

2. Lawan A. Congenital eye and adnexial anomalies in Kano, a five year review. Niger J Med. 2008;17:37-39.

3. Bodunde OT, Ajibode HA. Congenital eye diseases at Olabisi Onabanjo University Teaching Hospital, Sagamu, Nigeria. Niger J Med. 2006;15: 291-294.

4. Chuka-Okosa CM, Magulike NO, Onyekonwu GC. Congenital eye anomalies in Enugu, South-Eastern Nigeria. West Afr J Med. 2005;24: 112-114.

5. Kaimbo Wa Kaimbo D, Mwilambwe Wa Mwilambwe A, Kayembe DL, Leys A, Missoten L. Congenital malformations of the eyeball and its appendices in Zaire. Bull Soc Belge Ophtalmol. 1994;254:165-170. French.
6. Tchabi S, Sounouvou I, Yehouessi L, Doutetien C, Bassabi SK. Le glaucome congénital au CNHU de Cotonou: à propos de 27 cas [Congenital glaucoma at CNHU, Cotonou: a series of 27 cases]. Mali Med. 2007;22:14-17. French.

7. Safede K, Koffi KV, Kouassi FX, et al. Glaucome congenital: aspects cliniques et thérapeutiques [Congenital glaucoma: clinical and therapeutic aspects]. Med Afr Noire. 1999;46:264-267. French.

8. Zech JC, Ravault M. Traitement chirurgical du glaucome congénital. J Fr Ophtalmol. 1994;1:57-59.

9. Detry-Morel M, Feron EM. La trabéculectomie dans le traitement du glaucome congénital: expérience rétrospective à moyen et à long terme [Trabeculectomy in the treatment of congenital glaucoma: retrospective experience in the medium and long term]. Bull Soc Belge Ophtalmol. 1997;262:143-151. French.

10. Sevel D. Development and congenital abnormalities of the nasolacrimal apparatus. J Pediatr Ophthalmol Strabismus. 1981;18:13-19.

11. MacEwen CJ, Young JDH. Epiphora during the first year of life. Eye. 1991;5:596-600.

12. Otis PT, Shepherd R. Congenital Nasolacrymal duct obstruction: natural history and the timing of optimal intervention. $J$ Pediatr Ophthalmol Strabismus. 1994;31:362-367.

13. Parishit G, Clare G. La cécité infantile: panorama mondial [Childhood blindness: a worldwide review.]. Rev Sante Ocul Commun. 2008;5:37-39. French.

14. Sinskey RM, Amin PA, Lingua R. Cataract extraction and intraocular lens implantation in an infant with a monocular congenital cataract. J Cataract Refract Surg. 1994;20:647-651.

15. Onwasigwe EN. A survey of congenital ophthalmic anomalies in Nigerian children. Orient J Med. 2002;14:18-20.

16. Nacef L, Daghfous F, Marrakchi S. Le glaucome congénital en Tunisie. Profil épidémiologique, aspects cliniques et résultats thérapeutiques [Congenital glaucoma in Tunisia. Epidemiological profile, clinical aspects and theurapeutic results]. Ophtalmologie. 1994;8:28-32. French.

17. Shaw GM, Carmichael SL, Yang W, Harris JA, Finnell RH, Lammer EJ. Epidemiologic characteristics of anophthalmia and bilateral microphthalmia among 2.5 million births in California, 1989-1997. Am J Med Genet A. 2005;137:36-40.

18. Sakol PJ, Mannor G, Massaro BM. Congenital and acquired blepharoptosis. Curr Opin Ophthalmol. 1999;10:335-339.

19. Allard FD, Durairaj V. Current techniques in surgical correction of congenital ptosis. Middle East Afr J Ophthalmol. 2010;17:129-133.

20. Nelson LB, Spaeth GL, Nowinski TS, Margo CE, Jackson L. Aniridia. A review. Surv Ophthalmol. 1984;28:621-642.

21. Eden U, Iggman D, Ruse R, Tornqvist K. Epidemiology of aniridia in Sweden and Norway. Acta Ophthalmol. 2008;86:727-729.

22. Charif-Chefchaouni M, Hajji Z, EL Bakkali M, Boulanouar A, Berraho A. Les manifestations oculaires du syndrome de Marfan à propos de 20 cas [Ocular manifestations of Marfan's syndrome in a series of 20 cases]. Maghreb Med. 2001;87:33-37. French.

23. Ramirez F, Gayraud B, Pereira L. Marfan syndrome: new clues to genotype-phenotype correlations. Ann Med. 1999;31:202-207.

24. Ala-Mello S, Siggberg L, Knuutila S, Von Koskull H, Taskinen M, Peippo M. Familial transmission of oculoauriculovertebral spectrum. Am J Med Genet A. 2008;146:2490-2494.

25. Bijal M, Nayak S, Shankar S, Sangeeta A. Goldenhar syndrome with unusual features. Indian J Dermatol Venereol Leprol. 2008;74: 254-256.

26. Müllner-Eidenböck A, Amon M, Moser E, Klebermass N. Persistent fetal vasculature and minimal fetal vascular remnants: a frequent cause of unilateral congenital cataracts. Ophthalmology. 2004;111: 906-913. 
Clinical Ophthalmology

\section{Publish your work in this journal}

Clinical Ophthalmology is an international, peer-reviewed journal covering all subspecialties within ophthalmology. Key topics include: Optometry; Visual science; Pharmacology and drug therapy in eye diseases; Basic Sciences; Primary and Secondary eye care; Patien Safety and Quality of Care Improvements. This journal is indexed on

PubMed Central and CAS, and is the official journal of The Society of Clinical Ophthalmology (SCO). The manuscript management system is completely online and includes a very quick and fair peer-review system, which is all easy to use. Visit http://www.dovepress.com/ testimonials.php to read real quotes from published authors. 